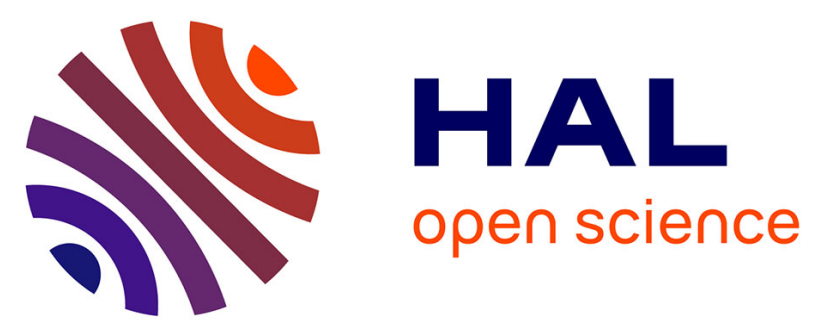

\title{
Dose-effect and metabolism of docosahexaenoic acid: Pathophysiological relevance in blood platelets.
}

\author{
Michel Lagarde, Catherine Calzada, Michel Guichardant, Evelyne Véricel
}

\section{To cite this version:}

Michel Lagarde, Catherine Calzada, Michel Guichardant, Evelyne Véricel. Dose-effect and metabolism of docosahexaenoic acid: Pathophysiological relevance in blood platelets.. Prostaglandins, Leukotrienes and Essential Fatty Acids, 2012, 88 (1), epub ahead of print. 10.1016/j.plefa.2012.04.001 . inserm-00691160

\section{HAL Id: inserm-00691160 https://www.hal.inserm.fr/inserm-00691160}

Submitted on 25 Apr 2012

HAL is a multi-disciplinary open access archive for the deposit and dissemination of scientific research documents, whether they are published or not. The documents may come from teaching and research institutions in France or abroad, or from public or private research centers.
L'archive ouverte pluridisciplinaire HAL, est destinée au dépôt et à la diffusion de documents scientifiques de niveau recherche, publiés ou non, émanant des établissements d'enseignement et de recherche français ou étrangers, des laboratoires publics ou privés. 


\title{
Dose-effect and metabolism of docosahexaenoic acid. Pathophysiological relevance in blood platelets.
}

\author{
Lagarde M, Calzada C, Guichardant M, Véricel E \\ Université de Lyon, UMR 1060 INSERM (CarMeN), IMBL, INSA-Lyon, France
}

\begin{abstract}
Docosahexaenoic acid (DHA) is known as a major nutrient from marine origin. Considering its beneficial effect in vascular risk prevention, the effect of DHA on blood components, especially platelets, will be reviewed here. Investigating the dose-effect of DHA in humans shows that daily intake lower than one gram/day brings several benefits, such as inhibition of platelet aggregation, resistance of monocytes against apoptosis, and reinforced antioxidant status in platelets and lowdensity lipoproteins. However, higher daily intake may be less efficient on those parameters, especially by losing the antioxidant effect. On the other hand, a focus on the inhibition of platelet aggregation by lipoxygenase end-products of DHA is made. The easy conversion of DHA by lipoxygenases and the formation of a double lipoxygenation product named protectin DX, reveal an original way for DHA to contribute in platelet inhibition through both the cyclooxygenase inhibition and the antagonism of thromboxane $A_{2}$ action.
\end{abstract}

\section{Introduction}

Docosahexaenoic acid (DHA) is considered as the major end-product of the omega- 3 essential fatty acids starting from the indispensable $\alpha$-linolenic acid in mammals. The conversion of the latter into the former is supposed to be low in humans, except in pregnant women (1). In addition to be the main polyunsaturated fatty acyl residue in the brain and retinal phospholipids (2), DHA is an important nutrient found in marine food, and it may accumulate in many cells to reach a few percent of membrane phospholipid fatty acyls, including blood cell membranes. It is assumed to play a positive role in preventing the cardiovascular risk (3). This could be due to structural effects, in relation to the folding of the molecule induced by its six cis/Z double bonds (4). Another possibility is to inhibit the conversion of arachidonic acid (ARA) at the level of the cyclooxygenase enzymes (5), then decreasing the formation of the atherothrombotic agent thromboxane (Tx) $A_{2}$ from ARA. In addition, DHA is easily oxygenated by lipoxygenases $(6,7)$ and some of their end-products may counteract the effect of $\mathrm{TxA}_{2}$ on its receptor site (8).

After its intake as esterified in triglycerides (fish or algal oil) or in phospholipids (fish meat), DHA is quickly distributed within blood lipoproteins (9) and made available to tissues, including blood cells, where it is transferred for esterification into membrane phospholipids $(10,11)$. The issue of the dose intake in dietary approaches is an important one as some studies have reported that, due to their high number of methylene interrupted double bonds, long-chain omega-3 polyunsaturated fatty acids (PUFA) such as DHA could be prone to peroxidation and could even promote it, depending on the amount ingested (12). The present manuscript addresses both that issue, especially focusing on blood platelets in their plasma environment, and the inhibition of platelet aggregation by lipoxygenase products of DHA.

\section{Dose-effect of DHA intake on blood cells and low-density lipoproteins}

Increased vascular risk in aging is a well-known situation (13). Investigation of platelet reactivity shows that platelets from elderly people respond more easily to aggregating agents, and that they contain lower amount of the antioxidant vitamin $E$, in relation to a higher production of malondialdehyde (MDA) considered as a global marker of lipid peroxidation within the cell $(14,15)$. On the other hand, increased lipid peroxidation in platelets can clearly be associated with higher aggregation response (16). It is then of interest to lower platelet reactivity through decreasing the peroxide tone of the cell (17). 
In that frame, low dosage of a mixture of long-chain omega-3 PUFA (DHA/eicosapentaenoic acid (EPA) with a 5/1 ratio) has been used, as compared with a placebo for six weeks. Interestingly, 180 $\mathrm{mg} /$ day of the mixture esterified in a triglyceride, restored platelet vitamin $\mathrm{E}$ while decreasing the MDA content (18). This positive effect of a low intake could be considered surprising, but confirmed previous results in a similar population after the intake of $100 \mathrm{mg} /$ day EPA for two months in the form of 1,3-octanoyl, 2-eicosapentaenoyl-glycerol (19). These results indicated that low intake of long-chain omega-3 PUFA may, at least in a population of elderly people that undergo oxidative stress, be beneficial for cardiovascular prevention through the regulation of platelet reactivity.

This issue has been more recently revisited in healthy volunteers who ingested increasing doses of DHA $(200,400,800 \& 1600 \mathrm{mg} /$ day DHA in algal triglycerides for two weeks each). Blood samples, obtained before and after each dose, and after a final wash out period, were processed for separation of platelets, polymorphonuclear leukocytes (PMNs), monocytes and plasma lipoproteins. The main results can be summarized as follows. DHA accumulated in plasma and cell glycerophospholipids in a dose-dependent manner, with a significant increase from the lowest dose $(200 \mathrm{mg} /$ day). Collagen-induced platelet aggregation was significantly inhibited after 400, 800 and $1600 \mathrm{mg} /$ day but the extent of inhibition was lower at the highest dose. Platelet vitamin $\mathrm{E}$ was significantly increased after the lowest dose, while it was increased in low-density lipoproteins (LDL) after the three lowest doses but not after the highest, with a reciprocal decrease of MDA $(20,21)$. In addition, LDL were significantly more resistant to copper-induced oxidation after the same lowest doses. Moreover, monocytes from the volunteers were also more resistant to oxidized LDL-induced apoptosis, especially after the middle dose of DHA (22). Finally, the overall marker of lipid peroxidation, the isoprostane 8-epi-PGF ${ }_{2 \alpha}$ in urine, was significantly lower and higher after 200 $\mathrm{mg} /$ day and $1600 \mathrm{mg} /$ day, respectively (20). The decrease of the generated leukotriene (LT) $B_{4}$ in calcium ionophore-stimulated PMNs was compensated by $\mathrm{LTB}_{5}$, which is known to be much less proinflammatory than $\mathrm{LTB}_{4}(23)$, and this was proportional to the intake of DHA (24). Altogether, these results indicate that, except for PMNs, cell functions were mostly affected after 400 and $800 \mathrm{mg} /$ day. These ex vivo findings are in accordance with results we obtained in vitro with platelets enriched with different concentrations of DHA (25). As far as the overall in vivo redox status is concerned, there was clearly an "antioxidant" effect of low doses of DHA that was masked at the highest dose of DHA intake with an even increased systemic oxidative stress as judged by urinary isoprostanes. The mechanism of action of such an antioxidant effect of DHA is unclear. However, the measurement of hydroxy-alkenals from omega- 3 and -6 PUFA might give a clue. The two relevant degradation products of hydroperoxide derivatives from the two series PUFA are 4-hydroxy-hexenal (4-HHE) and 4-hydroxy-nonenal $(4-\mathrm{HNE})$, respectively $(26,27)$. The measurement of both products showed that plasma 4-HHE increased in function of increasing doses of DHA while 4-HNE remained constant (21). This suggests that the DHA ingested was specifically peroxidized whereas the omega-6 PUFA of the body were not during the DHA supplementation. Although the amount of plasma 4-HHE measured only the free part of it, without considering the part covalently bound to primary amine- and thiolcontaining biomolecules, it was likely proportional to the amount produced. It might be then considered that DHA could be a preferential target of oxidative stress (although at a very low level compared to the amount ingested), then sparing other antioxidants such as vitamin $E$, until a certain level of intake for which the propagation of lipid peroxidation could mask the beneficial effects of the low intake. This speculative hypothesis is of interest in the current discussion on the dose-effect of long-chain omega-3 PUFA.

\section{Lipoxygenation of DHA and effect of the end-products on platelet aggregation}

The three main lipoxygenases acting upon ARA, namely 5-, 12- and 15-lipoxygenases, may oxygenate DHA at more than three carbon positions $(6,28)$, e.g. carbons 4 and 7 for 5 -lipoxygenase and carbons 11 and 14 for 12-lipoxygenase, in agreement with the multiple double bonds of the substrate. As platelet 12-lipoxygenase followed by the action of glutathione peroxidase produces substantial amounts of 11- and 14-hydroxy derivatives from DHA, these products were tested on platelet aggregation, and compared to the lipoxygenase end-product of ARA or EPA. Interestingly, the 
hydroxy derivatives from DHA were more potent to inhibit the $\mathrm{TXA}_{2}$-induced platelet aggregation than 12-HETE from ARA or 12-HEPE from EPA. The most potent of them, 14-OH-DHA (Figure 1), was also able to inhibit the $\mathrm{TxA}_{2}$-induced aorta contraction (8).

More recently, a series of papers from the group of Serhan have pointed out the great potential of DHA for being oxygenated into various derivatives with anti-inflammatory effects in different ways. These papers have reported on several docosanoids called protectins, resolvins and maresins (reviewed in 29 \& 30). One of them, protectin D1, has also been named neuroprotectin D1 because of its specific action on neuron cells (31). Based on these data, we have reconsidered the possibility of making a double lipoxygenation product of DHA able to inhibit platelet aggregation. To this end, DHA was incubated with soybean lipoxygenase, known to produce $17(\mathrm{~S})$-hydroperoxy-DHA, and a main dihydroxy derivative has been isolated and characterized as 10(S),17(S)-dihydroxy-docosa$4 Z, 7 Z, 11 E, 13 Z, 15 E, 19 Z$-hexaenoic acid by a series of physico-chemical methods, including high performance chromatography coupled with mass spectrometry and NMR (32). This product, named protectin DX (PDX) is an isomer of protectin D1 (PD1) or 10(R),17(S)-dihydroxy-docosa$4 Z, 7 Z, 11 E, 13 E, 15 Z, 19 Z$-hexaenoic acid. Interestingly, PDX, like many other oxygenated PUFA sharing the same $E, Z, E$ conjugated triene geometry (Figure 1), inhibits collagen- and ARA-induced platelet aggregation. In contrast, other conjugated triene products, such as $E, E, Z$ like in PD1 or $\mathrm{LTB}_{4}$, or all trans $(E, E, E)$ derivatives are not active against platelet aggregation (33). The $E, Z, E$ conjugated trienes obtained by the double lipoxygenation of PUFA have been named poxytrins. The mechanism of inhibition of platelet aggregation is double with an inhibition of cyclooxygenase 1 and the antagonistic action on $\mathrm{TxA}_{2}$ receptor site. In contrast, poxytrins are not active upon platelet 12lipoxygenase (33).

\section{Conclusion}

DHA is definitely an interesting nutrient in the prevention of blood platelet hyperaggregation, and we may consider its complementary effect compared to EPA that competes with ARA at the level of cyclooxygenase and is converted into prostanoids of different activities from those issued from ARA. DHA is not a prostanoid precursor but is assumed to be a potent inhibitor of cyclooxygenase. However, DHA is a fairly good substrate of lipoxygenases, of which the end-products are efficient inhibitors of thromboxane-induced platelet aggregation and for some of them (poxytrins), inhibitors of cyclooxygenase as well. The intake of DHA allows making it available from platelet membrane phospholipids for slowing down platelet aggregation through these mechanisms. In addition, DHA may exert an antioxidant effect due to its facility to be peroxidized, then being a preferential target of oxidative stress to spare other antioxidants. However, the intake of relatively high doses of DHA might exacerbate the peroxidation process and mask the beneficial effects of DHA through its action upon cyclooxygenase and via its lipoxygenase products. Figures $2 \& 3$ summarize the effects of DHA intake on blood parameters, and PDX (poxytrin from DHA) on blood platelets.

\section{Acknowledgements}

The authors thank the support of INSERM, the Ministry of Education and Research, and the LISA Carnot Institute.

\section{References}

1. G.C. Burdge, Metabolism of alpha-linolenic acid in humans, Prostaglandins Leukot Essent Fatty Acids 75 (2006) 161-168.

2. N. Salem Jr, B. Litman, H.Y. Kim, K. Gawrisch, Mechanisms of action of docosahexaenoic acid in the nervous system, Lipids 36 (2001) 945-959.

3. A. Leaf, J.X. Kang, Y.F. Xiao, Fish oil fatty acids as cardiovascular drugs, Curr Vasc Pharmacol 6 (2008) 11-12.

4. K.R. Applegate, J.A. Glomset, Computer-based modeling of the conformation and packing properties of docosahexaenoic acid, J Lipid Res 27 (1986) 658-680. 
5. G.H. Rao, E. Radha, J.G. White, Effect of docosahexaenoic acid (DHA) on arachidonic acid metabolism and platelet function, Biochem Biophys Res Commun 117 (1983) 549-555.

6. N.G. Bazan, D.L. Birkle, T.S. Reddy, Docosahexaenoic acid $(22: 6, n-3)$ is metabolized to lipoxygenase reaction products in the retina, Biochem Biophys Res Commun 125 (1984) 741-747.

7. M. Croset, M. Guichardant, M. Lagarde, Different metabolic behavior of long-chain n-3 polyunsaturated fatty acids in human platelets, Biochim Biophys Acta 961 (1988) 262-269.

8. M. Croset, A. Sala, G. Folco, M. Lagarde, Inhibition by lipoxygenase products of TXA2-like responses of platelets and vascular smooth muscle. 14-Hydroxy from 22:6n-3 is more potent than 12-HETE, Biochem Pharmacol 37 (1988) 1275-1280.

9. N. Brossard, M. Croset, J. Lecerf, C. Pachiaudi, S. Normand, V. Chirouze, O. Macovschi, J.P. Riou, J.L. Tayot, M. Lagarde, Metabolic fate of an oral tracer dose of [13C]docosahexaenoic acid triglycerides in the rat, Am J Physiol 270 (1996) R846-854.

10. N. Brossard, M. Croset, S. Normand, J. Pousin, J. Lecerf, M. Laville, J.L. Tayot, M. Lagarde, Human plasma albumin transports [13C]docosahexaenoic acid in two lipid forms to blood cells, J Lipid Res 38 (1997) 1571-1582.

11. D. Lemaitre-Delaunay, C. Pachiaudi, M. Laville, J. Pousin, M. Armstrong, M. Lagarde, Blood compartmental metabolism of docosahexaenoic acid (DHA) in humans after ingestion of a single dose of [(13)C]DHA in phosphatidylcholine, J Lipid Res 40 (1999) 1867-1874.

12. P. Palozza, E. Sgarlata, C. Luberto, E. Piccioni, M. Anti, G. Marra, F. Armelao, P. Franceschelli, G.M. Bartoli, n-3 fatty acids induce oxidative modifications in human erythrocytes depending on dose and duration of dietary supplementation, Am J Clin Nutr 64 (1996) 297-304.

13. S.S. Najjar, A. Scuteri, E.G. Lakatta, Arterial aging: is it an immutable cardiovascular risk factor?, Hypertension 46 (2005) 454-462.

14. E. Vericel, M. Croset, P. Sedivy, P. Courpron, M. Dechavanne, M. Lagarde, Platelets and aging. I-Aggregation, arachidonate metabolism and antioxidant status, Thromb Res 49 (1988) 331-342.

15. E. Vericel, C. Rey, C. Calzada, P. Haond, P.H. Chapuy, M. Lagarde, Age-related changes in arachidonic acid peroxidation and glutathione-peroxidase activity in human platelets, Prostaglandins 43 (1992) 75-85.

16. G. Hecker, J. Utz, R.J. Kupferschmidt, V. Ullrich, Low levels of hydrogen peroxide enhance platelet aggregation by cyclooxygenase activation, Eicosanoids 4 (1991) 107-113.

17. C. Calzada, E. Vericel, M. Lagarde, Low concentrations of lipid hydroperoxides prime human platelet aggregation specifically via cyclo-oxygenase activation, Biochem J 325 (1997) 495-500.

18. E. Véricel, C. Calzada, P. Chapuy, M. Lagarde, The influence of low intake of n-3 fatty acids on platelets in elderly people, Atherosclerosis 147 (1999) 187-192.

19. M. Croset, E. Véricel, M. Rigaud, M. Hanss, P. Courpron, M. Dechavanne, M. Lagarde, Functions and tocopherol content of blood platelets from elderly people after low intake of purified eicosapentaenoic acid, Thromb Res 57 (1990) 1-12.

20. N. Guillot, E. Caillet, M. Laville, C. Calzada, M. Lagarde, E. Véricel, Increasing intakes of the longchain omega-3 docosahexaenoic acid: effects on platelet functions and redox status in healthy men, FASEB J 23 (2009) 2909-2916.

21. C. Calzada, R. Colas, N. Guillot, M. Guichardant, M. Laville, E. Véricel, M. Lagarde, Subgram daily supplementation with docosahexaenoic acid protects low-density lipoproteins from oxidation in healthy men, Atherosclerosis 208 (2010) 467-472.

22. S. Mebarek, N. Ermak, A. Benzaria, S. Vicca, M. Dubois, G. Némoz, M. Laville, B. Lacour, E. Véricel, M. Lagarde, A.F. Prigent, Effects of increasing docosahexaenoic acid intake in human healthy volunteers on lymphocyte activation and monocyte apoptosis, Br J Nutr 101 (2009) 852-858.

23. D.W. Goldman, W.C. Pickett, E.J. Goetzl, Human neutrophil chemotactic and degranulating activities of leukotriene B5 (LTB5) derived from eicosapentaenoic acid, Biochem Biophys Res Commun 117 (1983) 282-288.

24. F. Stanke-Labesque, P. Molière, J. Bessard, M. Laville, E. Véricel, M. Lagarde, Effect of dietary supplementation with increasing doses of docosahexaenoic acid on neutrophil lipid composition and leukotriene production in human healthy volunteers, Br J Nutr 100 (2008) 829-833. 
25. E. Véricel, A. Polette, S. Bacot, C. Calzada, M. Lagarde, Pro- and antioxidant activities of docosahexaenoic acid on human blood platelets, J Thromb Haemost 1 (2003) 566-572.

26. M. Guichardant, S. Bacot, P. Molière, M. , Hydroxy-alkenals from the peroxidation of $n-3$ and $n-6$ fatty acids and urinary metabolites, Prostaglandins Leukot Essent Fatty Acids 75 (2006) 179-182.

27. A. Catalá, Lipid peroxidation of membrane phospholipids generates hydroxy-alkenals and oxidized phospholipids active in physiological and/or pathological conditions, Chem Phys Lipids 157 (2009) 1-11.

28. M.I. Aveldaño, H. Sprecher, Synthesis of hydroxy fatty acids from 4, 7, 10, 13, 16, 19-[1-14C] docosahexaenoic acid by human platelets, J Biol Chem 258 (1983) 9339-9343.

29. C.N. Serhan, M. Arita, S. Hong, K. Gotlinger, Resolvins, docosatrienes, and neuroprotectins, novel omega-3-derived mediators, and their endogenous aspirin-triggered epimers, Lipids 39 (2004) 11251132.

30. C.N. Serhan, Systems approach with inflammatory exudates uncovers novel anti-inflammatory and pro-resolving mediators, Prostaglandins Leukot Essent Fatty Acids 79 (2008) 157-163.

31. N.G. Bazan, J.M. Calandria, C.N. Serhan, Rescue and repair during photoreceptor cell renewal mediated by docosahexaenoic acid-derived neuroprotectin D1, J Lipid Res 51 (2010) 2018-2031.

32. P. Chen, B. Fenet, S. Michaud, N. Tomczyk, E. Véricel, M. Lagarde, M. Guichardant, Full characterization of PDX, a neuroprotectin/protectin D1 isomer, which inhibits blood platelet aggregation, FEBS Lett 583 (2009) 3478-3484.

33. P. Chen, E. Véricel, M. Lagarde, M. Guichardant, Poxytrins, a class of oxygenated products from polyunsaturated fatty acids, potently inhibit blood platelet aggregation, FASEB J 25 (2011) 382-388.

\section{Figure legends}

Figure 1: Chemical structures of DHA, its 12-/ $\omega 9$-lipoxygenase end-product 14[S]-HDHE, and its 15/ $\omega 6$ double lipoxygenase end-product 10[S],17[S]-diHDHE (PDX). HDHE, hydroxy-docosahexaenoic acid.

The $E, Z, E$ motif of the conjugated triene ( $\longrightarrow$ ), common in poxytrins, is responsible for the inhibition of platelet cyclooxygenase activity and antagonism of thromboxane $A_{2}$-induced aggregation.

Figure 2: Summary of the main variations observed in various blood parameters after successive intake of increasing doses of DHA. Ordinates represent relative variations for each parameter evaluated in function of the intake of DHA in abscissa.

Aggreg., platelet aggregation; HHE, 4-hydroxy-hexenal; HNE, hydroxyl-nonenal; Lag time, time elapsed for the appearance of conjugated dienes in response to copper-induced oxidation; vit. E; alpha-tocopherol; 8-epi-PGF ${ }_{2 \alpha}$, main isoprostane.

Figure 3: Metabolism of DHA by lipoxygenases and action of the hydroxylated end-products upon platelet cyclooxygenase (COX-1) and thromboxane $(T x) A_{2}$ receptor site, and in turn on platelet aggregation. $\longrightarrow$, metabolic pathway; $-\rightarrow$, action; decrease. 